\title{
Differentiation stage alters matrix control of stem cells
}

\author{
Susan X. Hsiong, ${ }^{1,2}$ Paolo Carampin ${ }^{2}$ Hyun-Joon Kong ${ }^{2,3}$ Kuen-Yong Lee, $^{4}$ David J. Mooney ${ }^{2}$ \\ ${ }^{1}$ Department of Chemical Engineering, University of Michigan, Ann Arbor, Michigan \\ ${ }^{2}$ School of Engineering and Applied Sciences, Harvard University, Cambridge, Massachusetts \\ ${ }^{3}$ Department of Chemical and Biomolecular Engineering, University of Illinois, Urbana, Illinois \\ ${ }^{4}$ Department of Bioengineering, Hanyang University, Seoul, South Korea
}

Received 1 November 2006; revised 22 January 2007; accepted 15 May 2007

Published online 9 August 2007 in Wiley InterScience (www.interscience.wiley.com). DOI: 10.1002/jbm.a.31521

\begin{abstract}
Cues from the material to which a cell is adherent (e.g., adhesion ligand presentation, substrate elastic modulus) clearly influence the phenotype of differentiated cells. However, it is currently unclear if stem cells respond similarly to these cues. This study examined how the overall density and nanoscale organization of a model cell adhesion ligand (arginine-glycine-aspartic acid [RGD] containing peptide) presented from hydrogels of varying stiffness regulated the proliferation of a clonally derived stem cell line (D1 cells) and preosteoblasts (MC3T3-E1). While the growth rate of MC3T3-E1 preosteoblasts was responsive to nanoscale RGD ligand organization and substrate
\end{abstract}

stiffness, the D1 stem cells were less sensitive to these cues in their uncommitted state. However, once the D1 cells were differentiated towards the osteoblast lineage, they became more responsive to these signals. These results demonstrate that the cell response to material cues is dependent on the stage of cell commitment or differentiation, and these findings will likely impact the design of biomaterials for tissue regeneration. (C) 2007 Wiley Periodicals, Inc. J Biomed Mater Res 85A: 145-156, 2008

Key words: biomaterial; extracellular matrix; cell differentiation; stem cells; osteoblasts

\section{INTRODUCTION}

The remarkable capability of stem cells to differentiate and express markers typical of a variety of cell types has led to the hope that they will one day be utilized to repair or regenerate tissues. ${ }^{1-4}$ Adult tissue-derived stem cell populations are particularly appealing for near-term applications due to their ready availability, and straightforward applicability to autologous cell transplantation therapies. However, to harness the potential of stems cells for cellbased therapies, their proliferation and differentiation must be tightly regulated. Microenvironmental cues, including soluble factors, cell-cell interactions, and extracellular matrix (ECM) signals, are clearly critical to this regulation. Most research to date has focused on the use of soluble signals to direct stem

Correspondence to: D. J. Mooney; e-mail: mooneyd@seas. harvard.edu

Contract grant sponsor: U.S. Army Research Laboratory and the U.S. Army Research Office; contract grant number: DAAD190310168

Contract grant sponsor: Ministero Istruzione Università Ricerca; contract grant number: PNR 2001-2003 (FIRB art. 8)

(C) 2007 Wiley Periodicals, Inc. cell fate, as both multipotent embryonic stem cells and less plastic cell populations derived from adult tissues are regulated by a variety of morphogens and growth factors. ${ }^{2,5}$

ECM cues, including the types and organization of adhesion ligands, and the physical properties (e.g. stiffness) of the substrate presenting these cues play important roles in defining the phenotype of differentiated cell populations, ${ }^{6-10}$ but it is currently unclear if stem cells similarly respond to these cues. ECM control over differentiated cell phenotype has provided a basis for the design of materials that can be used to manipulate these cells in vitro and in vivo, ${ }^{11-13}$ and these synthetic matrices are frequently a prominent component of cell-based therapies (e.g., engineered skin tissue). ${ }^{14-18}$ While it is anticipated that this approach will be similarly useful in stem cell therapies, the current lack of information regarding the ECM cue-stem cell fate relation hampers progress in the design of synthetic ECM analogs for these applications.

This study investigated how specific ECM cues (adhesion ligand density, spacing, and matrix stiffness) regulate the proliferation of a stem cell line, and compared this relation to that obtained with cells committed to a specific fate (preosteoblasts). A model ECM was used in this study, which consisted 
of an otherwise nonadhesive polysaccharide (alginate), in the physical form of a hydrogel, which presents covalently coupled cell adhesive ligands. Synthetic peptides containing the well-characterized arginine-glycine-aspartic acid (RGD) binding sequence for integrin receptors ${ }^{19}$ were used as the model adhesion ligand, and the density and organization of these peptides presented from the gels was varied. To vary the substrate elastic modulus, the extent of gel crosslinking was controlled. ${ }^{20}$

Two cell lines, a clonally derived stem cell line $(\mathrm{D} 1)^{21}$ derived from murine bone marrow, and a clonally derived murine preosteoblast line (MC3T3-E1), were selected and used to compare the dependence of stem cell versus differentiated cell proliferation on matrix cues. The use of clonally derived cell lines is critically important in these types of studies, as it allows one to directly determine if one is changing the fate of a cell type, versus the confounding issue of selecting for a subpopulation of cells in a heterogeneous population. ${ }^{22}$ The ability of D1 cells to differentiate down an osteoblast, chondrocyte, and adipocyte lineage has been described ${ }^{23-25}$ and their osteogenic differentiation in response to ascorbic acid and $\beta$-glycerophosphate has been well characterized. D1 cells express osteocalcin and type I collagen $(\alpha 1)_{2} \alpha 2$ mRNA as well as high levels of alkaline phosphatase and matrix mineralization in vitro. ${ }^{21}$ In addition, D1 cells loaded in diffusion chambers and implanted intraperitoneally in MF1 nu/nu athymic mice stained positively for alkaline phosphatase activity and matrix mineralization. ${ }^{21}$ The more committed MC3T3-E1 preosteoblasts are a commonly used model to study osteoblast differentiation. ${ }^{26-30}$ The preosteoblast cell response to matrix RGD ligand presentation and elastic modulus was first characterized in these studies and used to establish the committed cell response to matrix cues. The role of the stage of cell differentiation on the cell response to ECM cues was then studied with the D1 cells by comparing their response in the undifferentiated state to that in which the cells were induced toward the osteoblast lineage prior to studies on the role of ECM cues on their proliferation. Proliferation was utilized as an endpoint in these studies as it has previously been demonstrated that matrix properties such as RGD ligand presentation and degradation that control cell proliferation in vitro do result in profound functional differences in cell fate and tissue formation. ${ }^{13,31-33}$ For example, RGD ligand presentation from an alginate hydrogel not only enhanced MC3T3-E1 preosteoblast proliferation in vitro but also enhanced the extent of bone formed in a mouse subcutaneous model. ${ }^{13}$ Furthermore, properties such as scaffold degradation rate also regulate the amount of bone formed from human mesenchymal stem cells. ${ }^{33}$ Although the studies in this paper focused on the effects of adhesion ligand presentation on cell growth rate, these results likely have implications for longer term and functional effects on bone cell differentiation and formation.

\section{MATERIALS AND METHODS}

\section{Cell culture}

Murine preosteoblast MC3T3-E1-E1 cells, a generous gift from Dr. M. Kumegawa (Josai Dental University, Sakado, Japan), were cultured in $\alpha$-MEM media (without ascorbic acid; Invitrogen, Carlsbad, CA) supplemented with $10 \%$ fetal bovine serum (FBS; Invitrogen) and $100 \mathrm{U} / \mathrm{mL}$ penicillin-streptomycin (PS; Invitrogen). A mouse clonally derived bone marrow stromal cell line (D1 cells ${ }^{21}$; ATCC, Manassus, VA) was cultured in DMEM media (Invitrogen) supplemented with 10\% FBS (Invitrogen) and $100 \mathrm{U} / \mathrm{mL}$ PS. Human bone marrow stromal cells (hBMSCs) were isolated from bone marrow aspirate (National Disease Research Interchange, Philadelphia, PA) using Ficoll-Paque (GE Healthcare, Piscataway, NJ) and cultured in $\alpha$-MEM media (Invitrogen), 10\% FBS and $100 \mathrm{U} / \mathrm{mL}$ PS. For analysis of cell morphology, cells were labeled with octadecyl rhodamine B chloride R18 (Invitrogen) for $24 \mathrm{~h}$ prior to seeding, and photomicrographs were obtained $5 \mathrm{~h}$ postseeding using an Olympus IX81 (Melville, NY) inverted microscope and IP Lab software (Scanalytics, Rockville, $\mathrm{MD})$. All three cell types were seeded onto alginate substrates (no RGD, RGE and RGD [various spacings]) in serum-containing media.

\section{Preparation of adhesion substrates}

Peptide-modified alginate was prepared using standard carbodiimide chemistry as described previously ${ }^{34}$ from Ultrapure MVG (Pronova, Oslo, Norway) alginate and

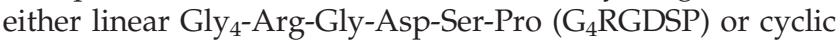
Gly $_{4}$-Cys-Arg-Gly-Asp-Ser-Pro-Cys ( $\left.\mathrm{G}_{4} \mathrm{CRGDSPC}\right)$ peptides for murine cell lines and human primary cells, respectively (Commonwealth Biotechnologies, Richmond, VA). In lieu of employing RGD-modified alginates with the extremely high DS required for hBMSC proliferation studies, we used cyclic RGD peptides which enhance cell adhesion and proliferation over linear RGD peptides. ${ }^{35}$ Alginates were reconstituted in $\alpha$-MEM media containing $1 \%$ PS to make a $2 \%$ hydrogel solution. All chemicals were obtained from Sigma-Aldrich (St. Louis, MO) unless otherwise noted. Alginate hydrogels were ionically crosslinked using calcium sulfate slurry in a 25:1 molar ratio before casting between glass plates. Disks (10 mm diameter, $1 \mathrm{~mm}$ thick) were made using an arch punch (McMaster-Carr, Atlanta, GA), and maintained in $\alpha$-MEM media with $1 \%$ PS overnight until cell seeding.

To vary the elastic moduli, hydrogels were prepared by varying the amount of crosslinking as previously described. ${ }^{36}$ Alginate hydrogels were prepared by mixing 1 part of $210 \mathrm{mg} / \mathrm{mL} \mathrm{CaSO}_{4}$ (Sigma) in water with 100, 25, 
12.5 parts of $2 \%(\mathrm{w} / \mathrm{w})$ alginate solution in $\alpha$-MEM to modulate the mechanical stiffness of the gels. The stiffness of the gels was evaluated by measuring the compressive elastic moduli $(E)$ with a mechanical tester (MTS Bionix 100; MTS systems, Eden Prairie, MN).

\section{Osteogenic predifferentiation}

In certain studies, D1 cells were predifferentiated for 14 days in DMEM media (Invitrogen) with 10\% FBS (Invitrogen) and $100 \mathrm{U} / \mathrm{mL}$ PS, supplemented with $10 \mathrm{ng} / \mathrm{mL}$ BMP-2 (Cell Sciences, Canton, MA), $50 \mu \mathrm{g} / \mathrm{mL}$ ascorbic acid, and $10 \mathrm{mM} \beta$-glycerophosphate (Sigma). For differentiation studies, D1 cells were expanded in DMEM media with $10 \%$ FBS (Invitrogen), $50 \mu \mathrm{g} / \mathrm{mL}$ ascorbic acid, and $100 \mathrm{U} / \mathrm{mL}$ PS, as described by Diduch et al. The state of differentiation was analyzed by quantifying calcium deposition and osteocalcin secretion, and staining for mineral deposition (von Kossa). The calcium content of cell lysates prepared by dissolving cultures with $1 \mathrm{M} \mathrm{HCl}$ was assayed using a calcium kit (Wako Pure Chemical, Japan) according to manufacturer's instructions. Osteocalcin levels in cell lysates prepared by incubating cells in passive lysis buffer (Promega, Madison, WI) were assayed using a mouse osteocalcin ELISA kit (Biomedical Technologies, Stoughton, MA) according to manufacturer's instructions. For staining, cell layers were fixed in $70 \%$ ethanol and a $5 \%$ silver nitrate solution was applied to the cell layer and exposed to light for $15 \mathrm{~min}$. Unreacted silver nitrate was removed by addition of $5 \%$ sodium thiosulfate. Cell layers were rinsed several times in PBS prior to obtaining von Kossa staining images with an Olympus IX81 (Melville, NY) inverted microscope.

\section{Cell proliferation}

Cells were seeded onto alginate disks at a seeding density of 10,000 cells $/ \mathrm{cm}^{2}$ and allowed to adhere for $5 \mathrm{~h}$. Disks were then transferred to new plates and fresh media was added. At $5 \mathrm{~h}$ and days 1, 2, and 4, disks were transferred to $15-\mathrm{mL}$ tubes containing $1 \mathrm{~mL}$ of trypsin (Invitrogen), incubated for $5 \mathrm{~min}\left(37^{\circ} \mathrm{C}\right)$, and $50 \mathrm{mM}$ EDTA/ PBS ( $\mathrm{pH}$ 7.4) was added to each tube to dissolve the disks. Cell counts from the solution were obtained using a Z2 Coulter Counter (Beckman Coulter, Fullerton, CA). Quadruplicate samples were assayed for each condition. Growth rates were calculated from cell counts comparing cell numbers at day 4 to cell numbers $5 \mathrm{~h}$ post-seeding. For ${ }^{3} \mathrm{H}$ thymidine incorporation, cells were incubated at each time point with $2 \mu \mathrm{Ci}{ }^{3} \mathrm{H}$ thymidine (Perkin Elmer, Wellesley, MA) for $24 \mathrm{~h}$. Media was removed and each disk was rinsed twice with cold PBS to remove unincorporated $3 \mathrm{H}$ thymidine. Disks were dissolved in $2 \mathrm{~mL}$ of $50 \mathrm{mM}$ EDTA/PBS ( $\mathrm{pH} 7.4)$ at $37^{\circ} \mathrm{C}$, and then centrifuged at $14,400 \mathrm{rpm}$ at $4^{\circ} \mathrm{C}$ for $5 \mathrm{~min}$. Upon removal of the supernatant, the cell pellet was rinsed in 5\% cold TCA in PBS and centrifuged again at $14,400 \mathrm{rpm}$. The cell pellet was solubilized in $0.5 \mathrm{~mL}$ of $10.25 \mathrm{~N} \mathrm{NaOH}$. Ultima Gold XR was added to each sample prior analysis using a TriCarb 2800TR liquid scintillation counter (Perkin Elmer).

\section{Reverse transcription-PCR}

D1 cells were seeded at 5000 cells $/ \mathrm{cm}^{2}$ in 12 -well tissue culture plates and cultured for 14 days in DMEM media only or with osteogenic supplements (as described earlier). At days 3 and 14, RNA was isolated from samples using a RNeasy mini kit (Qiagen). RNA was quantified using the Nanodrop (Nanodrop Technologies) and analyzed using the Bioanalyzer RNA Nano kit (Agilent Technologies). One microgram of each RNA sample was reverse transcribed to cDNA in a $50 \mu \mathrm{L}$ reaction using the high capacity cDNA archive kit (Applied Biosystems). The PCR reaction was performed using the primers for osteocalcin and GAPDH (Invitrogen) and the HotStarTaq Plus PCR kit (Qiagen) using a MJ Tetrad Thermal Cycler (Bio-Rad). Cycling conditions were: 5 min activation at $95^{\circ} \mathrm{C}, 1 \mathrm{~min}$ denaturation at $94^{\circ} \mathrm{C}, 1 \mathrm{~min}$ annealing at $60^{\circ} \mathrm{C}, 1 \mathrm{~min}$ extension at $72^{\circ} \mathrm{C}$ for 35 cycles, and a final extension for $10 \mathrm{~min}$ at $72^{\circ} \mathrm{C}$. Primer sequences (obtained from Yanai et al. ${ }^{37}$ ) from $5^{\prime}$ to $3^{\prime}$ :

\section{mOCN forward: CAAGTCCCACACAGCAGCTT mOCN reverse: AAAGCCGAGCTGCCAGAGTT mGAPDH forward: TGAAGGTCGGTGTGAACGGA TTTGGC \\ mGAPDH reverse: CATGTAGGCCATGAGGTCCAC CAC}

\section{Statistical analysis}

Values represent mean $(n=3$ or 4$)$ and standard deviation. Statistical significance of data was assessed using one way ANOVA with respect to substrate conditions for the respective experiment (either varying RGD island spacing, bulk density, or elastic modulus), followed by a post-hoc comparison using the Tukey test. * represents $p<0.05$ between noted conditions.

\section{RESULTS AND DISCUSSION}

To regulate adhesion ligand presentation to the cells in this study, the number of peptides per alginate chain (degree of substitution [DS]) was altered to control the total density of adhesion peptides presented from the material [Fig. 1(A)]. RGD-modified polymer chains were also combined with unmodified polymer chains (DS $=0$ ) at various ratios to create adhesive islands in the gels [Fig. 1(B)], and alter the nanoscale ligand spacing. ${ }^{38-40}$ The DS of the modified polymer chains can be altered in parallel with the island spacing to maintain an overall constant RGD total density in each series of gels, and the extent of ionic crosslinking was also manipulated to control the stiffness of the gel substrate from which the ligands were presented to cells (Table I).

The effect of adhesion peptide presentation (total density and nanoscale organization) on the adhesion of preosteoblasts and stem cells was first investigated. 
A

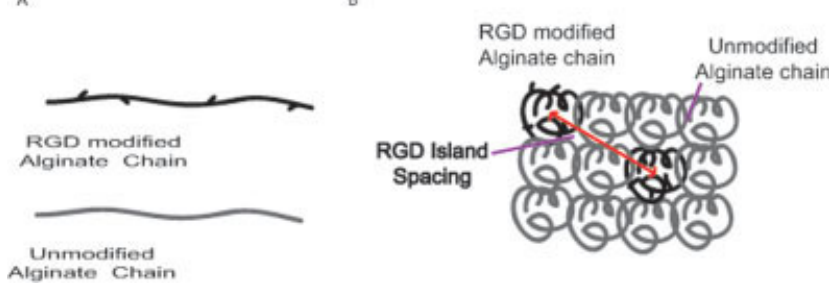

Figure 1. Experimental system. A: Polymer chains were either modified with coupled RGD peptides (DS 4 is shown; top) or left with no coupled RGD peptides (unmodified alginate, DS 0; bottom). B: The spacing between polymer chains containing RGD ligands (island spacing) was controlled by mixing RGD-modified alginate of various DS with unmodified alginate in various ratios. The overall RGD density (total density) was kept constant by altering DS in parallel with changes in island spacing. [Color figure can be viewed in the online issue, which is available at www.interscience.wiley.com.]

Alginate substrates which did not present RGD ligands did not promote proliferation of MC3T3 preosteoblasts and D1 stem cells (data not shown). However, both cell types readily adhered and spread on RGD-modified surfaces [Fig. 2(A,B)]. The number of cells adhered onto the RGD-modified alginates $5 \mathrm{~h}$ post-seeding were comparable across RGD island spacings examined in this study, presumably due to the presentation of the same overall RGD total density (although presented in different patterns) in this system. The MC3T3-E1 preosteoblasts were more elongated and spindle-shaped than the D1 stem cells; the projected area on the surface was greater for MC3T3 cells [Fig. 2(C)]. Overall cell spreading was decreased in cells seeded onto RGDpresenting substrates of increased RGD island spacings (data not shown). As a control, MC3T3 and D1 cells were cultured on surfaces presenting RGE peptides, a nonsense peptide sequence, to confirm that cell adhesion and proliferation in our experiments were RGD mediated. Although the cell numbers increased threefold $48 \mathrm{~h}$ post-seeding on the RGDmodified surfaces, the RGE-modified surfaces did not promote the growth of D1 cells [Fig. 2(D)] nor MC3T3 cells (data not shown).

The growth rate of the two cell types was then examined to determine the cell responsiveness to the density and nanoscale presentation of adhesion ligands. In these experiments, the DS (2-40) as well as the spacing between RGD islands (36-121 nm) was varied while maintaining a constant RGD total density (1.25, 6.25, or $12.5 \mathrm{mg} \mathrm{RGD} / \mathrm{g}$ alginate) across a series of island spacings. The growth rates of both stem cells and preosteoblasts generally increased as the total RGD density increased, although the sensitivity of the D1 cells to the total RGD density was slightly decreased, when com- pared with the MC3T3-E1 cells. The proliferation of both cell types was also dependent on the RGD island spacing at each constant RGD total density [Fig. 3(A,B)]. ${ }^{3} \mathrm{H}$ thymidine incorporation assays were used to analyze whether observed increases in cell numbers were due to an upregulation in DNA synthesis specifically, and this analysis corroborated the direct cell counts. DNA synthesis increased with the total RGD density and decreased as the RGD island spacing was increased from 36 to $121 \mathrm{~nm}$ [Fig. 3(C,D)]. These results are generally consistent with past studies demonstrating rat embryonic fibroblasts spreading and cell numbers increased as RGD ligand distances were decreased from 110 to 58 $\mathrm{nm},{ }^{41}$ and the importance of nanoscale RGD clustering and spacing on cell adhesion and motility. ${ }^{42}$ No significant cell apoptosis, assessed by annexin staining, was observed in these experiments (data not shown), indicating that the differences in cell numbers were directly related to changes in proliferation. To directly compare the dependency of preosteoblasts and stem cells on RGD presentation, cell growth rates on RGD-modified hydrogels were normalized, and D1 progenitor cell proliferation was clearly less responsive to RGD island spacing than MC3T3-E1 proliferation [Fig. 3(E)]. Normalization is with respect to the cell's growth rate at an RGD island spacing of $121 \mathrm{~nm}$ (overall RGD density of $12.5 \mathrm{mg} / \mathrm{g}$ alginate) for both cell types. The normalization trends observed for this ligand density also extends to a ligand density of $6.25 \mathrm{mg} / \mathrm{g}$ alginate, although the effect is less pronounced (data not shown). The trends observed were consistent within the range of ligand densities investigated.

The response of the committed cells to adhesion ligand presentation is typically dependent on the mechanical properties of the substrate presenting the peptides, ${ }^{8,40}$ and the elastic modulus $(E)$ of the adhesion substrate in these studies was varied to determine its effect on the growth rates of both cell types. Increasing the elastic modulus of the substrate enhanced MC3T3-E1 preosteoblast proliferation

TABLE I

Experimental Conditions Used in the Study

\begin{tabular}{cccc}
\hline DS RGD & $\begin{array}{c}\text { RGD Density } \\
(\mathrm{mg} / \mathrm{g} \text { alginate) }\end{array}$ & $\begin{array}{c}\text { Island } \\
\text { Spacing }(\mathrm{nm})\end{array}$ & $\begin{array}{c}\text { Elastic } \\
\text { Modulus }(\mathrm{kPa})\end{array}$ \\
\hline 0.2 & 1.25 & 85 & 60 \\
0.2 & 1.25 & 121 & 60 \\
1 & 6.25 & 36 & 60 \\
1 & 6.25 & 85 & 60 \\
1 & 6.25 & 121 & 60 \\
2 & 12.5 & 36 & $20,60,110$ \\
2 & 12.5 & 85 & 60 \\
2 & 12.5 & 121 & 60 \\
\hline
\end{tabular}



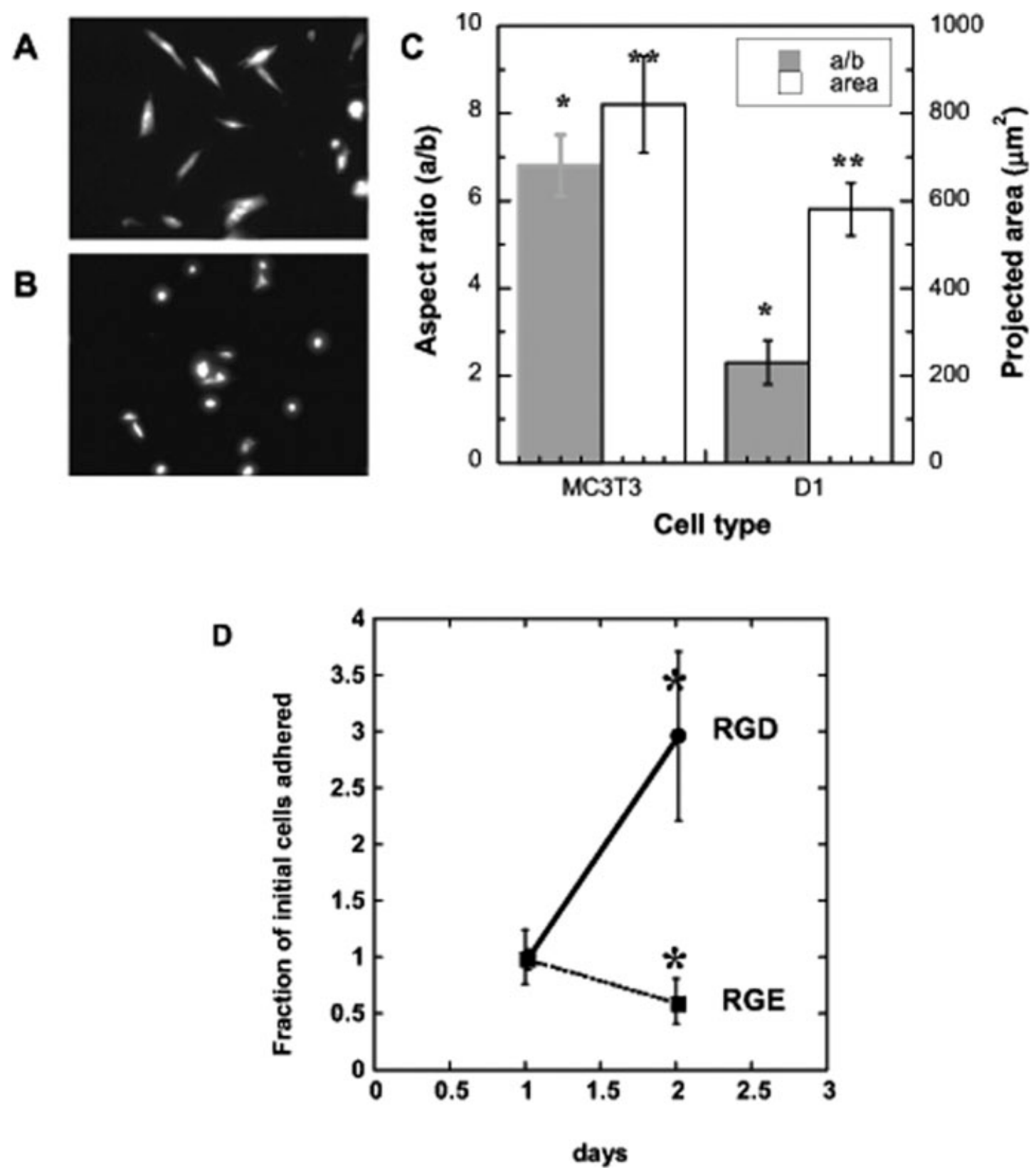

Figure 2. Cell adhesion and proliferation on RGD-modified alginate hydrogels. Fluorescent images of MC3T3 cells (A) and D1 cells (B) $5 \mathrm{~h}$ post-seeding onto RGD-modified hydrogels $(\times 200)$. C: The cell aspect ratio, defined as the ratio between long axis and short axis of cells, and projected areas of the two cell types on the substrate (RGD total density $12.5 \mathrm{mg}$ RGD/g alginate) in (A, B) as determined by image analysis of at least four disks per condition. D: The fraction of initial cells adhered on RGE- and RGD-modified substrates (total density $12.5 \mathrm{mg}$ RGE or RGD per g alginate). Values represent mean and standard deviation. * represents $p<0.05$ between the two cell types in (C) and RGE- and RGD-modified substrates (D).

[Fig. 4(A)], as anticipated from past studies. ${ }^{36}$ However, the proliferation of D1 stems cells was not dependent on the substrate elastic modulus [Fig. 4(B)]. Comparison of normalized MC3T3-E1 and D1 cell growth rates clearly demonstrate the difference in their dependency on substrate stiffness [Fig. 4(C)]. Altogether, these observations indicate that these stem cells were less responsive to matrix cues such as adhesion ligand presentation and substrate mechanical properties than the more committed cell line.

To confirm that the stage of differentiation controls cell proliferation dependence on matrix cues, the D1 cells were precultured in media with osteogenic supplements $(50 \mu \mathrm{g} / \mathrm{mL}$ ascorbic acid and $10 \mathrm{mM} \beta$-glycerophosphate ${ }^{21}$ ) to drive them down an 

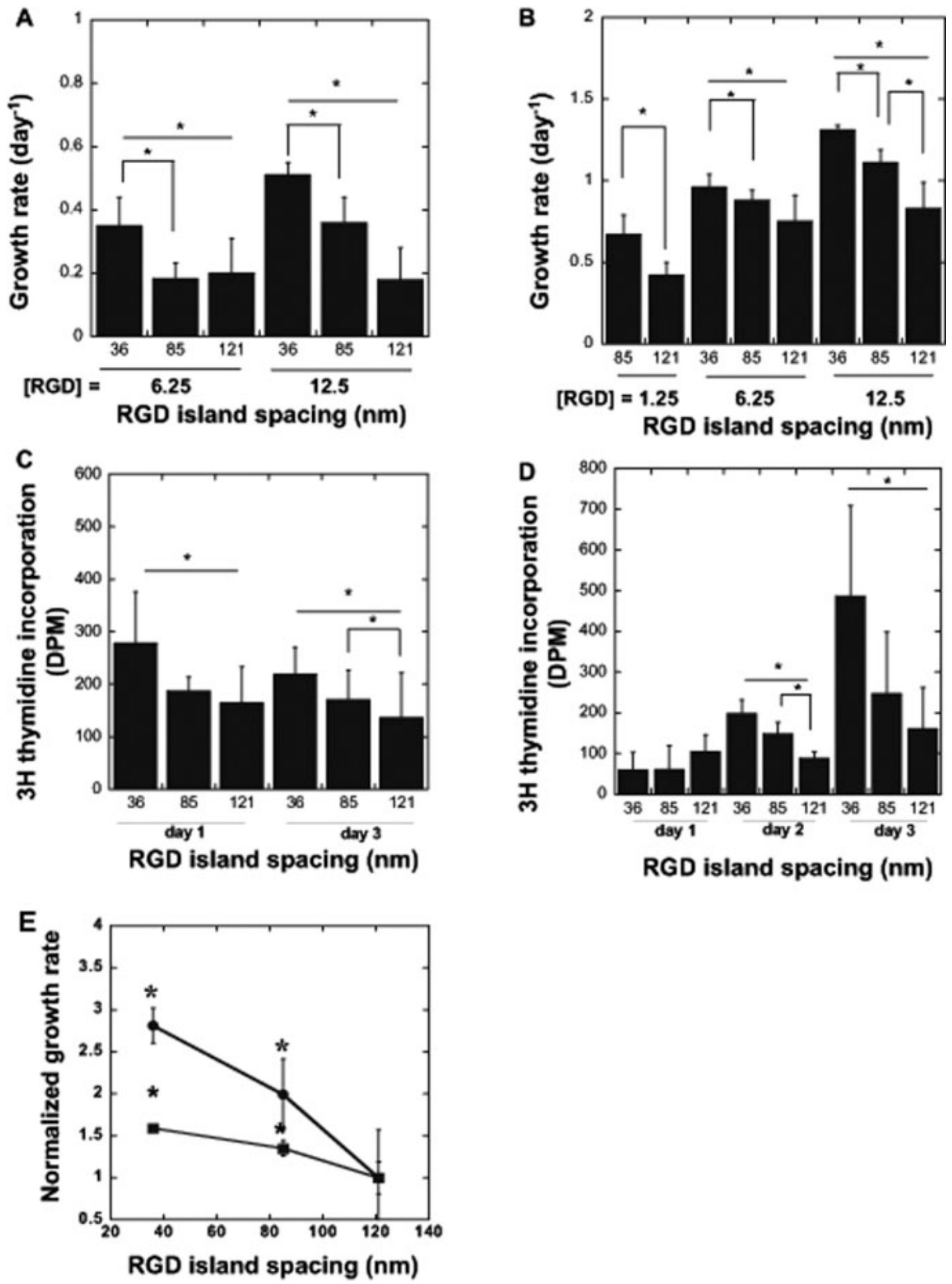

Figure 3. Growth rates and DNA synthesis of MC3T3 and D1 cells as RGD presentation is varied. MC3T3 (A, C) and D1 cells $(B, D)$ were cultured on gels that presented varying total densities of RGD ligands, and varying spacings between RGD islands. The growth rates of MC3T3 (A) and D1 cells (B), calculated from changes in cell number over time, were greater as the total RGD density was increased, but the growth rates decreased as the RGD island spacing increased at a constant RGD total density. Analysis of DNA synthesis in MC3T3 (C) and D1 cells (D) confirmed that cell proliferation was enhanced at lower RGD island spacings (overall RGD total density maintained at $12.5 \mathrm{mg} / \mathrm{g}$ alginate). E: Comparison of normalized growth rates of MC3T3 (circles) and D1 (squares) cells revealed that D1 cells were less sensitive to RGD island spacing than MC3T3 cells. Growth rates were normalized to that obtained with each cell type at the greatest island spacing (at a single ligand density of $12.5 \mathrm{mg} / \mathrm{g}$ alginate). The normalization trends observed for this ligand density also extends to ligand density of $6.25 \mathrm{mg} / \mathrm{g}$ alginate, although the effect is less pronounced. Values on all graphs represent mean and standard deviation $(n=4)$. ${ }^{*}$ represents $p<0.05$ between noted conditions in $(\mathrm{A}-\mathrm{E})$. [RGD] is RGD total density in mg/g alginate. 
A

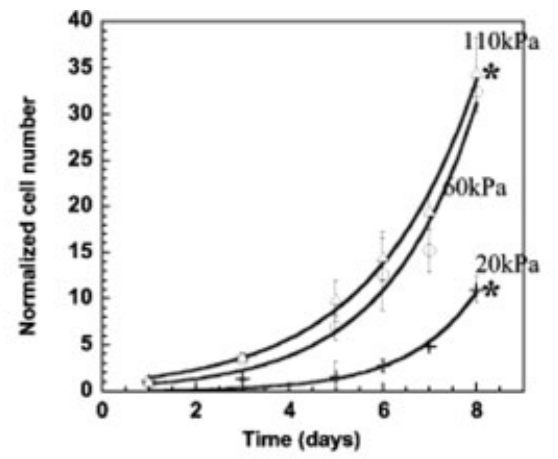

B

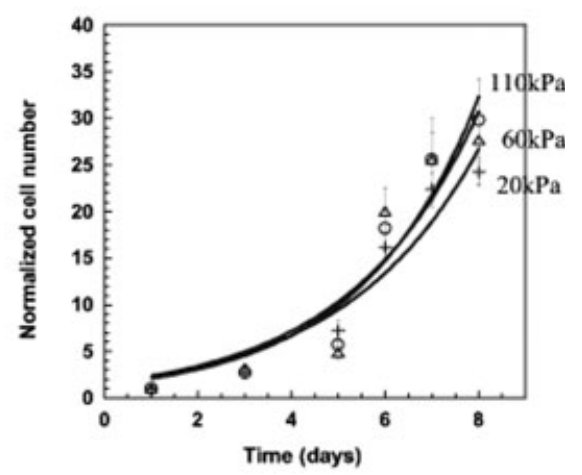

c

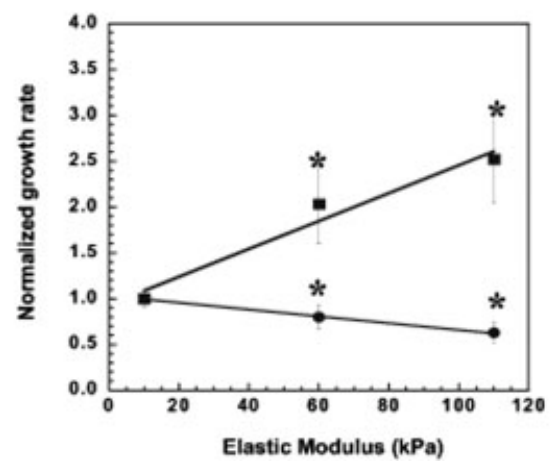

Figure 4. Substrate stiffness control of MC3T3 and D1 cell proliferation. Proliferation of MC3T3 (A) and D1 (B) cells when cultured on substrates presenting a constant, high total density of RGD (12.5 mg/g alginate) and island spacing (36 nm), but elastic modulus of $20 \mathrm{kPa}$ (cross), 60 $\mathrm{kPa}$ (open triangle), and $110 \mathrm{kPa}$ (open circles). C: Comparison of normalized growth rates, relative to growth rate on gels with modulus of $20 \mathrm{kPa}$, for MC3T3 preosteoblasts (closed squares) and D1 cells (closed circles). Values represent the mean and standard deviation from three independent experiments. Differences between the values on the two highest modulus substrates and the lowest were statistically significant in (A), as noted by * $(p<0.05)$, but not in (B). Differences between growth rates between the cell types as the moduli were varied were also statistically significant in $(C)$, as noted by $*(p<0.05)$.

osteogenic pathway before matrix studies were performed. The D1 cells cultured in this media mineralized over time [Fig. 5(B)], whereas D1 cells cultured in media without osteogenic supplements [Fig. 5(A)] did not mineralize, as demonstrated by von Kossa staining. Lysates of D1 cells cultured with and with- out osteogenic supplements were also quantitatively assayed for calcium deposition [indicative of mineralization; Fig. 5(C)] and osteocalcin [Fig. 5(D)], a late stage bone specific marker. To confirm previously published data, osteocalcin mRNA levels were also assessed; osteocalcin mRNA was observed in D1 cells cultured in the presence of osteogenic supplements [Fig. 5(E)]. These assays confirmed that the D1 cells differentiated toward an osteoblast phenotype when cultured in media with the osteogenic supplements (these cells will be referred to as predifferentiated D1 cells). It was also observed that addition of recombinant human bone morphogenetic protein 2 (BMP-2) with ascorbic acid and $\beta$ glycerophosphate enhanced the differentiation and mineralization of the D1 cells (data not shown).

Predifferentiated D1 cells were subsequently cultured on substrates with varying RGD presentation and elastic moduli, and their proliferation quantified. Strikingly, increasing the RGD density enhanced the growth rate of these predifferentiated D1 cells [Fig. 6(A)], and these predifferentiated D1 cells showed a similar response to adhesion ligand density as the MC3T3-E1 cells. The predifferentiated D1 cell growth rates were also quite sensitive to RGD island spacings [Fig. 6(B)]. Indeed, comparison of normalized proliferation rates of these cells to the MC3T3-E1 and undifferentiated D1 cells indicated that predifferentiation made the $\mathrm{D} 1$ cells as responsive to RGD presentation as the MC3T3-E1 cells, and more responsive than the undifferentiated D1 cells [Fig. $6(C)]$. The growth rates of predifferentiated D1 cells were also enhanced as the substrate elastic modulus was increased, in a similar manner as observed for the MC3T3-E1 preosteoblasts [Fig. 6(D)].

In all of these experiments, well-characterized, clonally derived cell lines were used to investigate ECM cues on cell growth. These experiments were next extended by performing similar experiments with the primary hBMSCs widely used in tissue regeneration and engineering studies as these cells have recently been demonstrated to respond to geometric and mechanical cues from the adhesion substrate. ${ }^{22,43,44} \mathrm{We}$ investigated the growth rate response of the heterogeneous hBMSC population to RGD ligand presentation and substrate stiffness and compared how the cell response differed from that of a clonally derived cell population. HBMSC growth was strongly influenced by total RGD density and island spacing [Fig. $7(\mathrm{~A}, \mathrm{~B})]$. This dependence was similar in magnitude to that of MC3T3-E1 cells, and much greater than that observed with D1 cells before they were differentiated. Increasing the substrate elastic modulus (at a constant overall RGD density of $125 \mathrm{mg} / \mathrm{g}$ alginate) also led to greater hBMSC proliferation [Fig. 7(C)], and their response to this cue was similar to the MC3T3-E1 response. Again, the magnitude of this 
A

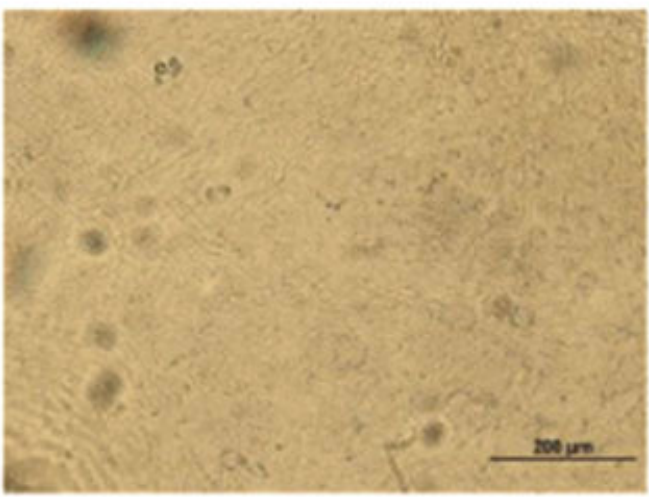

C

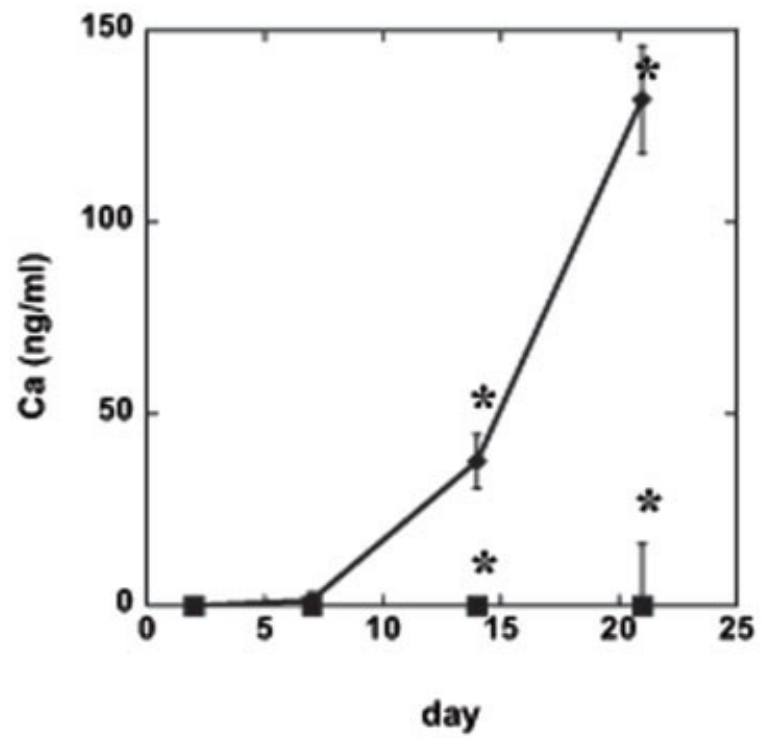

E
B

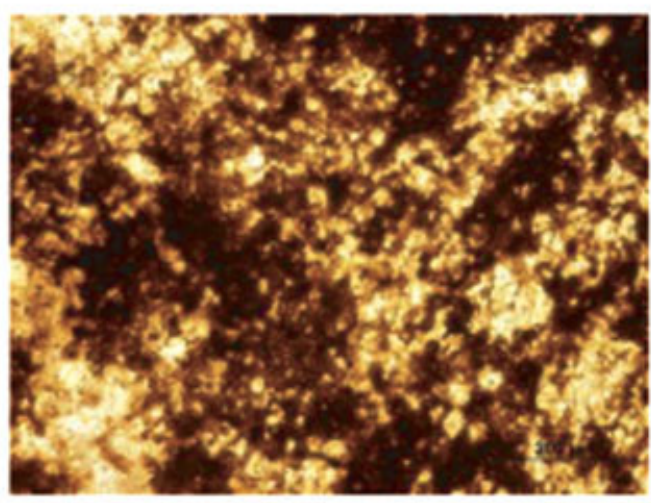

D

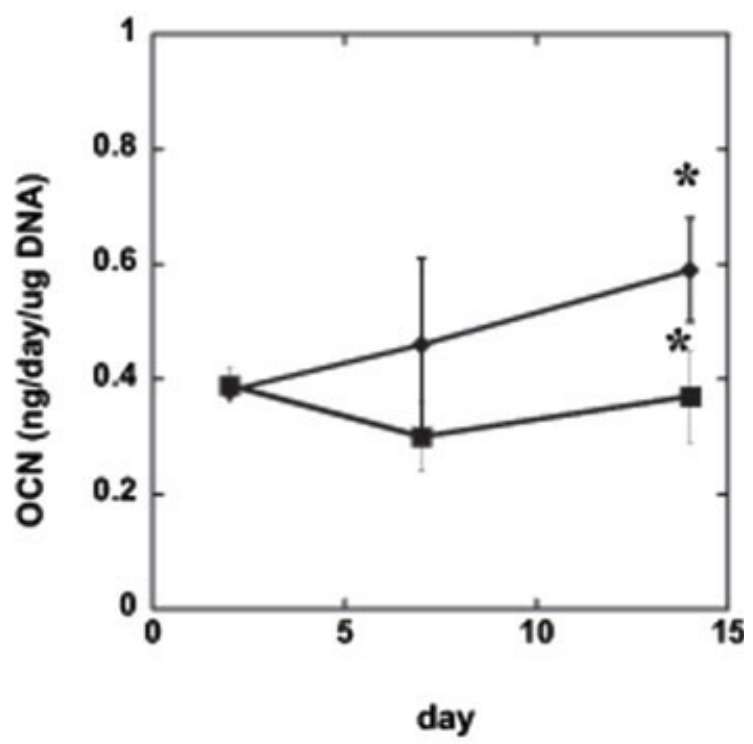

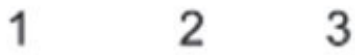

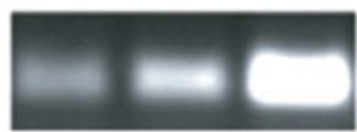

$\mathrm{OCN}$

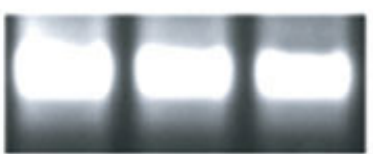

GAPDH

Figure 5. Differentiation of D1 stem cells in osteogenic media. D1 cells cultured in media without (A) and with (B) osteogenic supplements $(50 \mu \mathrm{g} / \mathrm{mL}$ ascorbic acid and $10 \mathrm{mM} \beta$-glycerophosphate) were qualitatively assessed for matrix mineralization via von Kossa staining. Addition of osteogenic supplements resulted in positive staining (dark regions) for mineralization. To quantify the extent of cell differentiation, the calcium content (C) in the cultures, and osteocalcin secretion (D) of cells cultured with (triangles) and without (squares) osteogenic supplements were analyzed. E: Osteogenic differentiation was also assessed at the genetic level using reverse-transcriptase PCR. Osteocalcin mRNA was observed in samples cultured in the presence of osteogenic supplements (lanes 1-3 [day 14], triplicate samples). Message levels for a housekeeping gene, GAPDH, are also shown for each condition to demonstrate evenness of loading. Values represent mean and standard deviation $(n=3)$. * represents $p<0.05$ between control and condition in which supplements were added. [Color figure can be viewed in the online issue, which is available at www.interscience.wiley.com.] 

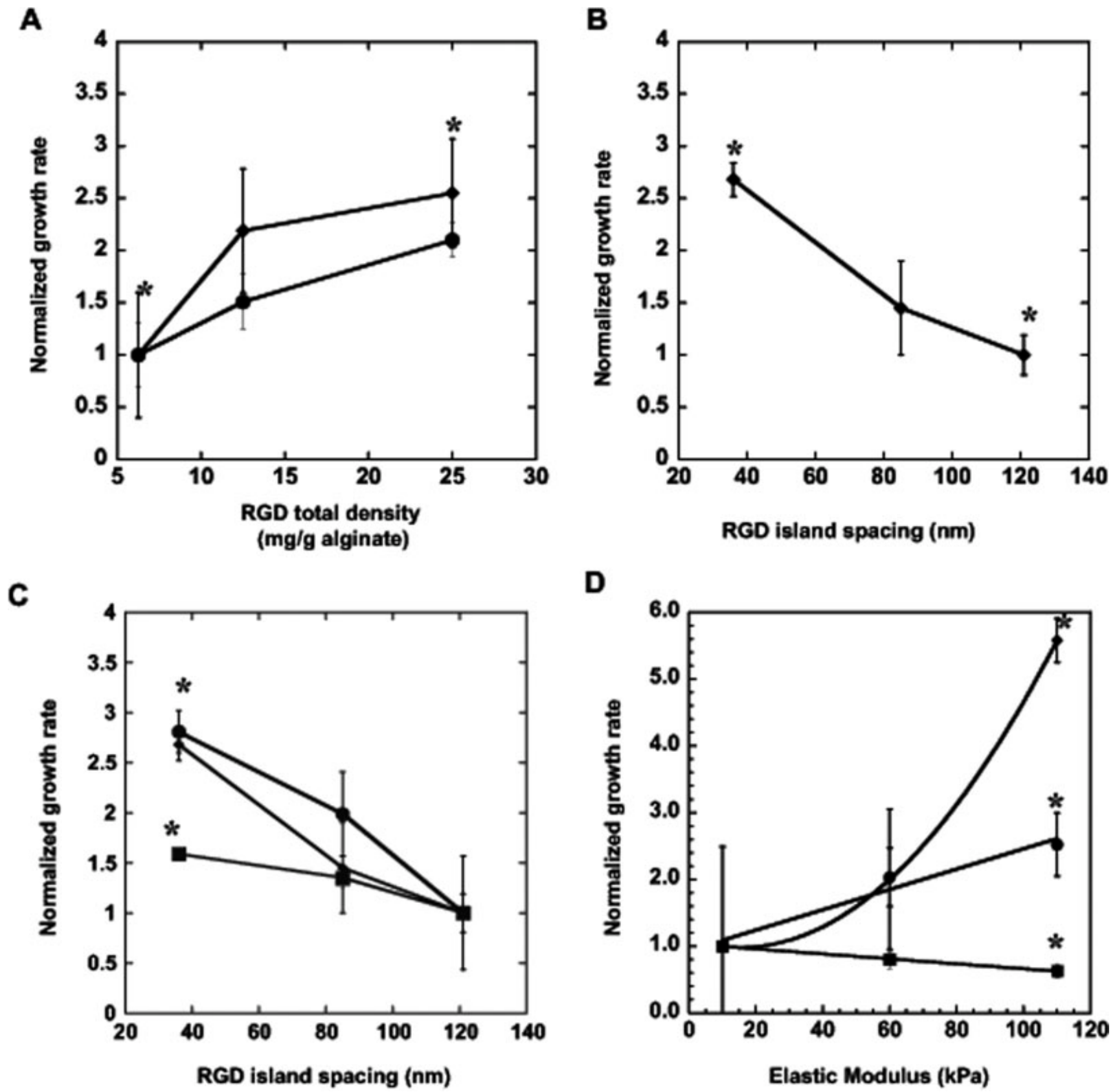

Figure 6. Proliferation of predifferentiated D1 cells and MC3T3 preosteoblasts in response to RGD total density and island spacing. D1 cells were cultured in DMEM media with osteogenic supplements for 14 days (termed predifferentiated D1 cells) prior to seeding onto RGD-modified hydrogels. The normalized growth rates of predifferentiated D1 (diamonds) and MC3T3-E1 cells (circles) were determined as a function of total RGD density (A) and decreasing RGD island spacing (overall RGD total density maintained at $12.5 \mathrm{mg} / \mathrm{g}$ alginate) (B). C: Normalization of growth rates, relative to lowest value in each condition, revealed that predifferentiated D1 cells (diamonds) responded in a similar manner to the RGD island spacing as MC3T3 preosteoblasts (circles). D: Similarly, comparison of the normalized growth rates of D1 stem cells (squares), predifferentiated D1 cells (diamonds), and MC3T3 preosteoblasts (circles) revealed that the predifferentiated D1 cells were much more sensitive to the substrate elastic modulus than the undifferentiated D1 cells (constant RGD total density of $12 \mathrm{mg} / \mathrm{g}$ alginate, and constant island spacing of $36 \mathrm{~nm}$ for all cell types). Values represent mean and standard deviation $(n=4)$. * represent $p<0.05$ between values as RGD total density and spacing increased (A, B), and between undifferentiated D1 and both the MC3T3 preosteoblasts and predifferentiated D1s in (C) and the different cell types in (D).

effect was greater than that observed for D1 cells prior to their differentiation, and similar to that observed with predifferentiated D1 cells. Interest- ingly, the response of hBMSCs to RGD ligand presentation is intermediate to that of MC3T3-E1 preosteoblasts and undifferentiated D1 cells. This finding 

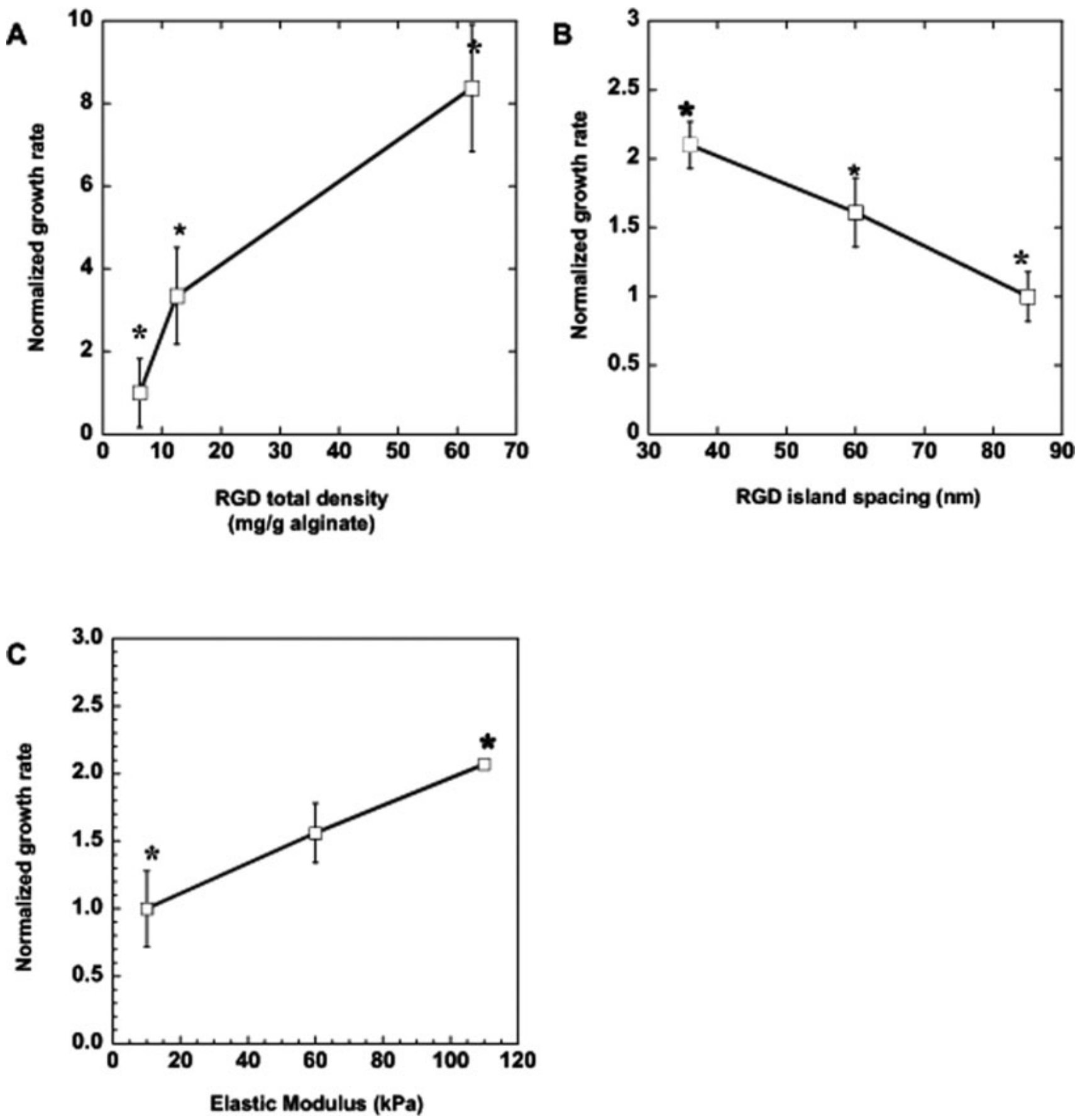

Figure 7. Proliferation of hBMSC in response to total RGD density, island spacing, and substrate stiffness. Elastic modulus of all conditions was maintained at $60 \mathrm{kPa}$ for these studies. (A) The hBMSC growth rate increased with RGD density (linear), and (B) with decreasing RGD island spacing (overall cyclic RGD density of $15.2 \mathrm{mg} / \mathrm{g}$ alginate). C: Increases in the substrate elastic modulus led to significant increases in hBMSC proliferation rates (overall RGD density of $12.5 \mathrm{mg} / \mathrm{g}$ alginate). Values represent mean and standard deviation $(n=4)$. ${ }^{*}$ represents $p<0.05$ between noted conditions.

suggests that, functionally, this cell population is either at an intermediate stage of differentiation or this heterogeneous population contains a mixture of more primitive and lineage-committed cells.

These studies clearly indicate that the stage of differentiation regulates the cell responses to matrix cues. D1 stem cells that were less responsive to matrix cues in their uncommitted state became more sensitive to these signals once they were differentiated towards the osteoblast lineage. The mechanism of this transition is unclear, but may be related to changes in the types or numbers of integrins (cell surface receptors which mediate ECM interactions) expressed in committed versus progenitor cell 
populations. It has been reported that stromal progenitors constitutively express the laminin receptor, $\alpha 6 \beta 1$, but lack expression of the collagen/laminin receptor, $\alpha 3 \beta 1$, whereas osteoblast-like cells express $\alpha 3 \beta 1$ but lack expression of $\alpha 6 \beta 1 .{ }^{45}$ As cells differentiate, expression of specific integrins (e.g. $\alpha v \beta 3$ ) may be upregulated while others (e.g. $\beta 1$ integrins) are downregulated, as observed with studies using MC3T3 preosteoblasts. ${ }^{46}$ Integrin receptors containing the $\beta 1$ subunit are likely to be especially important in the interaction of osteoblast-like cells with their $\mathrm{ECM}^{45,47}$ and alter the cell response to RGDligand presentation and substrate stiffness. Alternatively, as progenitor cells differentiate, their production of enzymes and machinery to control matrix formation may be altered and thus may feedback to modify cell responsiveness to the ECM, ${ }^{48}$ or the intracellular signal transduction pathways triggered by matrix cues may be altered.

It is widely known that cells are not only sensitive to substrate stiffness, ${ }^{49}$ but the cell response is also dependent on the cell type. ${ }^{10,50}$ Hepatocytes require soft substrates to maintain function and a differentiated phenotype, whereas myocytes appear to require stiffer substrates for myotube formation. Osteoblasts are typically in an environment in which they are surrounded by a relatively rigid matrix of collagen and mineral with an elastic modulus of $\sim 100 \mathrm{kPa}^{43}$ It is possible that stem cells committed toward the osteoblast phenotype will exhibit the osteoblast preference for a stiffer substrate and thus the predifferentiated D1 stem cells may become more responsive to substrates with higher elastic modulus in a similar manner as has been reported for hBMSCs. ${ }^{43}$ However, it is difficult to discern whether the effects of matrix stiffness on hBMSC commitment toward specific lineages are due to a change in cell fate or a selection for the presence of progenitors already committed to various lineages. The use of a clonally derived stem cell population in these studies allows us to more rigorously examine how ECM cues influence a homogeneous stem cell population, and eliminates the potentially confounding effects due to the presence of other progenitor cell types.

Successful cell-based therapies for tissue regeneration require the rational design of optimally designed biomaterials. The results of this study suggest that the biomaterial design is not "one size fits all" and must be tailored to the specific stage of cell differentiation. In this study, we demonstrate that the presentation of RGD ligands and substrate stiffness exert different effects on osteoprogenitors, depending on their stage of differentiation. These effects are anticipated to be relevant to many other progenitor and stem cell populations as well. Further understanding of how progenitor cells and committed cells respond to substrate cues may allow one to engineer synthetic microenvironments to direct cell fate and drive tissue regeneration and/or reverse disease states.

We thank Wendy A. Comisar for providing the scheme in Figure 1(A,B).

\section{References}

1. Caplan AI, Bruder SP. Mesenchymal stem cells: Building blocks for molecular medicine in the 21st century. Trends Mol Med 2001;7:259-264.

2. Pittenger MF, Mackay AM, Beck SC, Jaiswal RK, Douglas R, Mosca JD, Moorman MA, Simonetti DW, Craig S, Marshak DR. Multilineage potential of adult human mesenchymal stem cells. Science 1999;284:143-147.

3. Bianco P, Riminucci M, Gronthos S, Robey PG. Bone marrow stromal stem cells: Nature, biology, and potential applications. Stem Cells 2001;19:180-192.

4. Weissman IL. Translating stem and progenitor cell biology to the clinic: Barriers and opportunities. Science 2000;287:14421446.

5. Yao S, Chen S, Clark J, Hao E, Beattie GM, Hayek A, Ding S. Long-term self-renewal and directed differentiation of human embryonic stem cells in chemically defined conditions. Proc Natl Acad Sci USA 2006;103:6907-6912.

6. Rezania A, Healy KE. The effect of peptide surface density on mineralization of a matrix deposited by osteogenic cells. J Biomed Mater Res 2000;52:595-600.

7. Pelham RJ Jr, Wang YL. Cell locomotion and focal adhesions are regulated by the mechanical properties of the substrate. Biol Bull 1998;194:348-349; discussion 349-350.

8. Engler A, Bacakova L, Newman C, Hategan A, Griffin M, Discher D. Substrate compliance versus ligand density in cell on gel responses. Biophys J 2004;86 (Part 1):617-628.

9. Massia SP, Hubbell JA. Vascular endothelial cell adhesion and spreading promoted by the peptide REDV of the IIICS region of plasma fibronectin is mediated by integrin $\alpha 4 \beta 1$. J Biol Chem 1992;267:14019-14026.

10. Discher DE, Janmey P, Wang YL. Tissue cells feel and respond to the stiffness of their substrate. Science 2005;310: 1139-1143.

11. Hern DL, Hubbell JA. Incorporation of adhesion peptides into nonadhesive hydrogels useful for tissue resurfacing. J Biomed Mater Res 1998;39:266-276.

12. Massia SP, Rao SS, Hubbell JA. Covalently immobilized laminin peptide Tyr-Ile-Gly-Ser-Arg (YIGSR) supports cell spreading and co-localization of the 67-kilodalton laminin receptor with $\alpha$-actinin and vinculin. J Biol Chem 1993;268:8053-8059.

13. Alsberg E, Anderson KW, Albeiruti A, Franceschi RT, Mooney DJ. Cell-interactive alginate hydrogels for bone tissue engineering. J Dent Res 2001;80:2025-2029.

14. Hansbrough JF, Dore C, Hansbrough WB. Clinical trials of a living dermal tissue replacement placed beneath meshed, split-thickness skin grafts on excised burn wounds. J Burn Care Rehabil 1992;13:519-529.

15. Eaglstein WH, Falanga V. Tissue engineering and the development of Apligraf, a human skin equivalent. Clin Ther 1997; 19:894-905.

16. Levenberg S, Rouwkema J, Macdonald M, Garfein ES, Kohane DS, Darland DC, Marini R, van Blitterswijk CA, Mulligan RC, D'Amore PA, Langer R. Engineering vascularized skeletal muscle tissue. Nat Biotechnol 2005;23:879-884.

17. Vacanti JP, Langer R, Upton J, Marler JJ. Transplantation of cells in matrices for tissue regeneration. Adv Drug Deliv Rev 1998;33:165-182. 
18. Patel N, Padera R, Sanders GH, Cannizzaro SM, Davies MC, Langer R, Roberts CJ, Tendler SJ, Williams PM, Shakesheff KM. Spatially controlled cell engineering on biodegradable polymer surfaces. Faseb J 1998;12:1447-1454.

19. Ruoslahti E. RGD and other recognition sequences for integrins. Annu Rev Cell Dev Biol 1996;12:697-715.

20. Kong HJ, Liu J, Riddle K, Matsumoto T, Leach K, Mooney DJ. Non-viral gene delivery regulated by stiffness of cell adhesion substrates. Nat Mater 2005;4:460-464.

21. Diduch DR, Coe MR, Joyner C, Owen ME, Balian G. Two cell lines from bone marrow that differ in terms of collagen synthesis, osteogenic characteristics, and matrix mineralization. J Bone Joint Surg Am 1993;75:92-105.

22. Krebsbach PH, Kuznetsov SA, Bianco P, Robey PG. Bone marrow stromal cells: Characterization and clinical application. Crit Rev Oral Biol Med 1999;10:165-181.

23. Li X, Cui Q, Kao C, Wang GJ, Balian G. Lovastatin inhibits adipogenic and stimulates osteogenic differentiation by suppressing PPARgamma2 and increasing Cbfa1/Runx2 expression in bone marrow mesenchymal cell cultures. Bone 2003; 33:652-659.

24. Li X, Jin L, Cui Q, Wang GJ, Balian G. Steroid effects on osteogenesis through mesenchymal cell gene expression. Osteoporos Int 2005;16:101-108.

25. Devine MJ, Mierisch CM, Jang E, Anderson PC, Balian G. Transplanted bone marrow cells localize to fracture callus in a mouse model. J Orthop Res 2002;20:1232-1239.

26. Sudo H, Kodama HA, Amagai Y, Yamamoto S, Kasai S. In vitro differentiation and calcification in a new clonal osteogenic cell line derived from newborn mouse calvaria. J Cell Biol 1983;96:191-198.

27. Franceschi RT, Iyer BS, Cui Y. Effects of ascorbic acid on collagen matrix formation and osteoblast differentiation in murine MC3T3-E1 cells. J Bone Miner Res 1994;9:843-854.

28. Nakatani Y, Tsunoi M, Hakeda Y, Kurihara N, Fujita K, Kumegawa M. Effects of parathyroid hormone on cAMP production and alkaline phosphatase activity in osteoblastic clone MC3T3E1 cells. Biochem Biophys Res Commun 1984;123:894-898.

29. Suzuki A, Ghayor C, Guicheux J, Magne D, Quillard S, Kakita A, Ono Y, Miura Y, Oiso Y, Itoh M, Caverzasio J. Enhanced expression of the inorganic phosphate transporter Pit-1 is involved in BMP-2-induced matrix mineralization in osteoblast-like cells. J Bone Miner Res 2006;21:674-683.

30. Lian JB, Shalhoub V, Aslam F, Frenkel B, Green J, Hamrah M, Stein GS, Stein JL. Species-specific glucocorticoid and 1,25-dihydroxyvitamin D responsiveness in mouse MC3T3-E1 osteoblasts: Dexamethasone inhibits osteoblast differentiation and vitamin D down-regulates osteocalcin gene expression. Endocrinology 1997;138:2117-2127.

31. Yang F, Williams CG, Wang DA, Lee H, Manson PN, Elisseeff J. The effect of incorporating RGD adhesive peptide in polyethylene glycol diacrylate hydrogel on osteogenesis of bone marrow stromal cells. Biomaterials 2005;26:5991-5998.

32. Alsberg E, Kong HJ, Hirano Y, Smith MK, Albeiruti A, Mooney DJ. Regulating bone formation via controlled scaffold degradation. J Dent Res 2003;82:903-908.

33. Simmons CA, Alsberg E, Hsiong S, Kim WJ, Mooney DJ. Dual growth factor delivery and controlled scaffold degradation enhance in vivo bone formation by transplanted bone marrow stromal cells. Bone 2004;35:562-569.

34. Rowley JA, Madlambayan G, Mooney DJ. Alginate hydrogels as synthetic extracellular matrix materials. Biomaterials 1999; 20:45-53.
35. Kato M, Mrksich M. Using model substrates to study the dependence of focal adhesion formation on the affinity of integrin-ligand complexes. Biochemistry 2004;43:2699-2707.

36. Kong HJ, Polte TR, Alsberg E, Mooney DJ. FRET measurements of cell-traction forces and nano-scale clustering of adhesion ligands varied by substrate stiffness. Proc Natl Acad Sci USA 2005;102:4300-4305.

37. Yanai $\mathrm{T}$, Katagiri $\mathrm{T}$, Akiyama S, Imada M, Yamashita $\mathrm{T}$, Chiba H, Takahashi N, Suda T. Expression of mouse osteocalcin transcripts, OG1 and OG2, is differently regulated in bone tissues and osteoblast cultures. J Bone Miner Metab 2001;19:345-351.

38. Lee KY, Alsberg E, Hsiong S, Comisar W, Linderman J, Ziff $\mathrm{R}$, Mooney DJ. Nanoscale adhesion ligand organization regulates osteoblast proliferation and differentiation. Nano Lett 2004;4:1501-1506.

39. Comisar WA, Hsiong SX, Kong HJ, Mooney DJ, Linderman JJ. Multi-scale modeling to predict ligand presentation within RGD nanopatterned hydrogels. Biomaterials 2006;27:23222329.

40. Koo LY, Irvine DJ, Mayes AM, Lauffenburger DA, Griffith LG. Co-regulation of cell adhesion by nanoscale RGD organization and mechanical stimulus. J Cell Sci 2002;115(Part 7):1423-1433.

41. Cavalcanti-Adam EA, Micoulet A, Blummel J, Auernheimer J, Kessler H, Spatz JP. Lateral spacing of integrin ligands influences cell spreading and focal adhesion assembly. Eur J Cell Biol 2006;85:219-224.

42. Maheshwari G, Brown G, Lauffenburger DA, Wells A, Griffith LG. Cell adhesion and motility depend on nanoscale RGD clustering. J Cell Sci 2000;113(Part 10):1677-1686.

43. Engler AJ, Sen S, Sweeney HL, Discher DE. Matrix elasticity directs stem cell lineage specification. Cell 2006;126:677-689.

44. Chen CS, Mrksich M, Huang S, Whitesides GM, Ingber DE. Geometric control of cell life and death. Science 1997;276: 1425-1428.

45. Gronthos S, Simmons PJ, Graves SE, Robey PG. Integrinmediated interactions between human bone marrow stromal precursor cells and the extracellular matrix. Bone 2001;28: 174-181.

46. Cheng SL, Lai CF, Blystone SD, Avioli LV. Bone mineralization and osteoblast differentiation are negatively modulated by integrin $\alpha(v) \beta 3$. J Bone Miner Res 2001;16:277-288.

47. Xiao G, Wang D, Benson MD, Karsenty G, Franceschi RT. Role of the $\alpha 2$-integrin in osteoblast-specific gene expression and activation of the Osf2 transcription factor. J Biol Chem 1998;273:32988-32994.

48. Malaval L, Liu F, Roche P, Aubin JE. Kinetics of osteoprogenitor proliferation and osteoblast differentiation in vitro. J Cell Biochem 1999;74:616-627.

49. Pelham RJ Jr, Wang Y. Cell locomotion and focal adhesions are regulated by substrate flexibility. Proc Natl Acad Sci USA 1997;94:13661-13665.

50. Georges PC, Janmey PA. Cell type-specific response to growth on soft materials. J Appl Physiol 2005;98:1547-1553.

51. Stein GS, Lian JB, Gerstenfeld LG, Shalhoub V, Aronow M, Owen T, Markose E. The onset and progression of osteoblast differentiation is functionally related to cellular proliferation. Connect Tissue Res 1989;20:3-13.

52. Stein GS, Lian JB. Molecular mechanisms mediating proliferation/differentiation interrelationships during progressive development of the osteoblast phenotype. Endocr Rev 1993; 14:424-442. 